\title{
El Atlas de Gerhard Richter
}

\author{
Francesco GIAVERI \\ Universidad Complutense de Madrid. Departamento de Historia del Arte III
}

\begin{abstract}
RESUMEN
En 1962 Gerhard Richter empieza a coleccionar fotografías y a guardarlas en cajas de cartón; es una actividad que continúa, sin interrupciones, a lo largo de toda su vida, y que se vincula estrechamente con su investigación artística. Recoge fotografías propias y de revistas, imágenes privadas y recortes de enciclopedias y periódicos, que conserva sin distinciones y sin indicar las fuentes. El motivo principal, que movió a Richter a comenzar y a seguir trabajando en este proyecto, es fundamentalmente una necesidad de crear un cosmos ordenado frente al aluvión de las imágenes.
\end{abstract}

Palabras clave: Richter; atlas; pintura; montaje; fotografía.

\section{Gerhard Richter's Atlas}

\begin{abstract}
In 1962 Gerhard Richter began to collect photographs and store them in cardboard boxes. It's an on going activity that continues, without interruption throughout is life. It's closely engaged with his artistic research. He takes both his own photographs and the megazine's ones, private images and cuts of enciclopedias and newspapers, which saved without indications nor sources. The main reason that move Richter to begin and keep working on this project is primarily a need to create a tidy cosmos against the alluvial of images.
\end{abstract}

Keywords: Richter, atlas, painting, montage, photography.

\section{Multiplicidades}

En 1962 Gerhard Richter empieza a coleccionar fotografías y a guardarlas en cajas de cartón. El artista continuará esta actividad a lo largo de toda su vida y la vinculará estrechamente con su investigación artística ${ }^{1}$. Al principio, confluirían en el Atlas los modelos iconográficos de sus pinturas, y en concreto, los Fotobilder realizados entre 1962 y 1964, cuyos originales fotográficos se hallan todos en los primeros paneles del álbum. Con el torrencial aumento de las imágenes que lo

1 "El Atlas es [...] el palimpsesto del inconsciente (individual y colectivo), que sustenta y tiende a dominar la obra pictórica." En CHEVRIER, Jean-Francois, "Entre las Bellas Artes y los media (el ejemplo alemán: Gerhard Richter)", en Fotografia y Pintura en la obra de Gerhard Richter, MACBA, Barcelona, 1999 , p. 184. 
componen (más de 5.000), la relación con las pinturas de Richter se hace menos directa. Esto permite considerar al Atlas como una obra autónoma; y como obra autónoma, se ha presentado en numerosas ocasiones ${ }^{2}$.

El material que compone el Atlas es fuertemente heterogéneo: fotografías encontradas, recortes de revistas, fotografías tomadas por el artista, collages, esbozos, dibujos, proyectos expositivos y ejercicios experimentales sobre las imágenes. Como dijo en su momento Buchloh: "aparentemente documentos mudos, sin trascendencia"3.

La clasificación de este material responde a dos criterios fundamentales. El primero, por contenido, según el tema representado y el segundo es un criterio formal (dimensión y forma). Resulta claro, desde el comienzo, precisamente por la vacuidad de los criterios escogidos, que nos encontramos frente a una obra inacabable y difícilmente reducible a una definición única que la describa en su totalidad ${ }^{4}$. Resulta ciertamente arduo decir en qué consiste el Atlas y describirlo, sin embargo, es lícito avanzar hipótesis sobre su funcionalidad con respecto a la actividad del artista, que dedica a este proyecto casi cuatro décadas. ¿Se trata de una herramienta de conocimiento de su propia percepción (y, por extensión de sí mismo $\mathrm{s}^{5}$ y del mundo? La personal iconosfera y la educada visión del artista están necesariamente entrelazadas. Este cruce lleva el Atlas ha actuar como un espejo, una peculiar versión de una autobiografía por imágenes. En este sentido, es posible hallar líneas narrativas que parecen volver siempre a lo $\mathrm{mismo}^{6}$, pese a las múltiples lecturas que ofrece. El enlace que une todas las imágenes es la curiosidad del autor, que le mueve a constituir este fondo que compulsivamente organiza. Aquí la imagen correcta, testada y confrontada con las demás, aflora. Entonces Richter la reconoce y la emplea, sometiéndola a una ulterior transformación, convirtiéndola en pintura. Quiere partir del documento antiartístico para luego plasmarlo en un óleo sobre lienzo. "Se diría que Richter copia pacientemente los reflejos fotográficos del mundo contemporáneo, a la espera de que se produzca el milagro: el encuentro del motivo emblemático; a veces se produce, a veces no"?

2 Cabe recordar, entre otras, las exposiciones de Utrecht (1972), Krefeld (1976), Munich (1989), Colonia (1990), Paris (1993), Nueva York (1995). En la Documenta X (1997) Catherine David le otorga un papel importante en su discurso expositivo en el Fridericianum, junto a la Section Publicité de Broodthaers, reflexionando sobre la relación entre documento y hecho artístico.

3 BUCHLOH, Benjamin H.D., "El Atlas de Gerhard Richter: el archivo anómico", en Fotografia y Pintura en la obra de Gerhard Richter, MACBA, Barcelona, 1999, p. 161.

4 Coleccionar, guardar y exponer aquel material, que constituye la base de sus obras, ha sido considerado como parte de la estrategia artística de Richter. Véase FRIEDEL, Helmut (dir.), Gerhard Richter Atlas. Photographs, Collages and Sketches. 1962 -2006, Thames\&Hudson, 2006, p. 6.

5 BALDACCI, Cristina, Il duplice volto dell'Atlas di Gerhard Richter, en Leitmotiv, nº 4, 2004, p. 213.

6 FRIEDEL, Helmut (dir.) (2006), op. cit., p. 5.

7 ROCHLITZ, Rainer, "El punto en el que nos hallamos", en Fotografia y Pintura en la obra de Gerhard Richter, MACBA, Barcelona, 1999. p. 257. 
Trataremos más adelante el tema de la banalidad de la mayoría de estas fotografías, que parece ser uno de los requisitos fundamentales a la hora de añadirlas al Atlas. El artista, de forma provocativa, llegó a escribir que "algunas fotos de aficionado" parecen "mejores que el mejor Cézanne". Si la pintura es una manera de ver, su modelo a copiar no es el mundo fenoménico, sino el mediatizado. Richter escribe: "Pintar a partir de una fotografía forma parte del proceso de trabajo. No es una característica distintiva de mi visión, es decir, no sustituyo la realidad con una reproducción de ella, con un mundo de segunda mano. Yo recurro a la fotografía como Rembrandt recurrió al dibujo y Vermeer a la cámara oscura, para hacer un cuadro" .

Puede ser que, efectivamente, Richter no llegue a sustituir la realidad con un mundo de segunda mano, sin embargo es cierto que pone a prueba su visión del mundo a partir de sus reproducciones fotográficas. El Atlas es el palimpsesto entre la realidad y la manera (pictórica) de ver de Richter. Quizá sea esta estructura la que le impide creer en la equivalencia entre la realidad e imágenes. Éstas últimas pasan por su "mesa de trabajo" 10 donde el artista las desmonta y las reproduce después de una metamorfosis, que sugiere también una forma de apropiación ${ }^{11}$.

Richter colecciona fotografías propias o de revistas, imágenes privadas o recortes de enciclopedias y periódicos, las conserva sin distinciones y sin indicar las fuentes. Después de guardarlas en cajas de cartón decide colocarlas, a partir de 1969 , en paneles blancos de tamaño estándar: $50 \times 65 \mathrm{~cm}, 50 \times 70 \mathrm{~cm}$ y $50 \times 35 \mathrm{~cm}$. Cada panel constituye una unidad donde los elementos que la componen se relacionan entre ellos sintáctica y semánticamente. Un atlas no funciona como un archivo, cada tabla permite una visión de conjunto, que aumenta notablemente durante las exposiciones.

Todo puede encontrar cabida en el Atlas, el entorno familiar del artista y las pruebas de colores, los lager nazis y los recortes pornográficos, paisajes y bodegones, fotografías de obras de Beuys en Nápoles en 1986 y retratos de Blinky Palermo, ciudades y campos, mares y montañas y un largo etcétera (783 paneles hasta hoy). Funciona como una referencia fácilmente manejable por los que se acercan a la obra de Richter porque el Atlas es tanto una herramienta de trabajo como un inventario de sus intereses formales.

8 CHEVRIER, Jean-Francois (1999), op. cit., p. 174.

9 RICHTER, Gerhard, "Notas, 1964-1965", en PICAZO, Gloria y RIBALTA, Jorge (eds.), Indiferencia y singularidad: la fotografia en el pensamiento artístico contemporáneo, Gustavo Gili, Barcelona, 2003, p. 20.

10 DIDI - HUBERMAN, Georges, Atlas ¿Cómo llevar el mundo a cuestas?, TF, Madrid, 2010, p. 40. Este catálogo es fundamental en el estudio de las colecciones de imágenes bajo la influencia del método de Aby Warburg. Se publicó cuando el presente artículo ya estaba ampliamente estructurado, por lo tanto, se le tiene en cuenta aquí solo en parte.

11 Véase BUCHLOH, Benjamin H.D., "Procedimiento alegóricos: apropiación y montaje en el arte contemporáneo”, en PICAZO, Gloria y RIBALTA, Jorge (eds.) (2003) op. cit., pp. 99-132. 
El Atlas es también un instrumento de experimentación sujeto a cambios. Cuando se instala, Richter renuncia a presentarlo en su totalidad, altera incluso el orden que tiene en su forma-libro y lo dispone de la manera más oportuna con respecto al espacio que lo acoge; buscando un diálogo con la arquitectura de las salas. Una preocupación que se puede hallar fácilmente dentro del Atlas, donde se juega con las disposiciones de las formas en el espacio, y se recrea el espacio arquitectónico para verificar el funcionamiento de una obra. El artista, en muchas ocasiones, crea pequeñas maquetas donde estudia la instalación de una imagen (fotográfica, pegada en el panel) en un espacio (ficticio, dibujado con líneas en perspectivas) ${ }^{12}$, en algunas, llega incluso a dibujar los espectadores ${ }^{13}$.

El Atlas es un organismo ${ }^{14}$ en constante mutación. Múltiple y en distintos niveles: contenidos, formas, usos y, desde luego, significados. El motivo principal, que movió Richter a comenzar y a seguir trabajando en este proyecto, es una necesidad

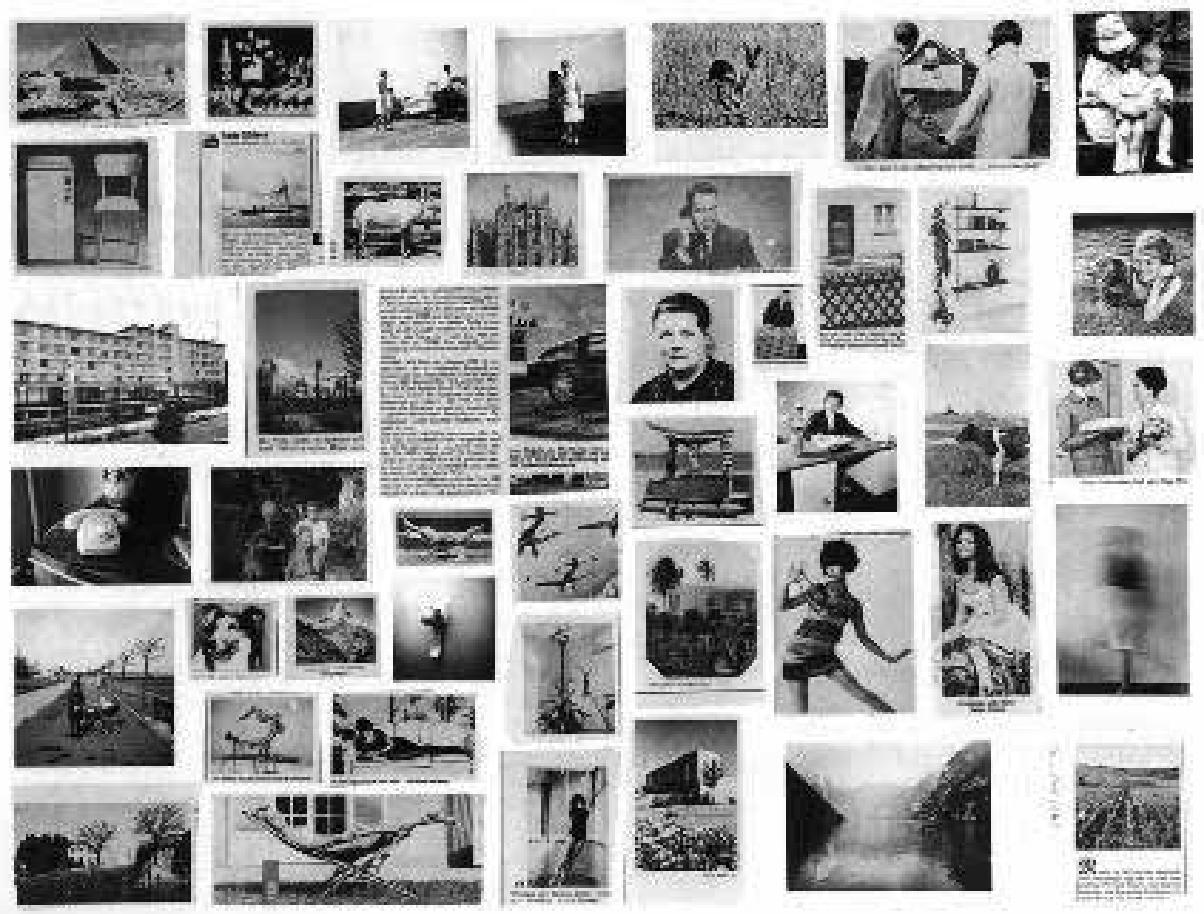

Fig. 1. Fotografías de periódicos y álbumes, 1962, $51.7 \mathrm{~cm}$ x $66.7 \mathrm{~cm}$, Panel de Atlas de Gerhard Richter, $\mathrm{n}^{\circ} 5$.

\footnotetext{
12 Véanse los paneles 40, 103, 122, 123, de 219 a 253, 394, de 647 a 655. Presenta también la maqueta de un libro: de 697 a 736.

13 Véanse los paneles 254, 410, 650, 651, de 653 a 655.

14 FRIEDEL, Helmut (dir.) (2006), op. cit., p. 17.
} 
de crear un cosmos, a la vez público y privado, frente al aluvión de las imágenes: "mi motivación fue principalmente la necesidad de crear un orden, mantener un hilo conductor de las cosas. Todas estas cajas de fotografías, esbozos te echan abajo, porque son incompletos, no finitos. Así que es mejor presentar el material utilizable en manera ordenada y tirar las demás cosas. Así es como nació el Atlas, y como lo he expuesto algunas veces"15. Esta necesidad de orden avanza a través de un método heurístico. El artista experimenta con imágenes heterogéneas que dispone en paneles a través del método del montaje. Todo el material que confluye en el Atlas no está producido específicamente para este proyecto, es preexistente, el artista lo rescata del abandono. En lugar de archivarlas separadamente, acaban

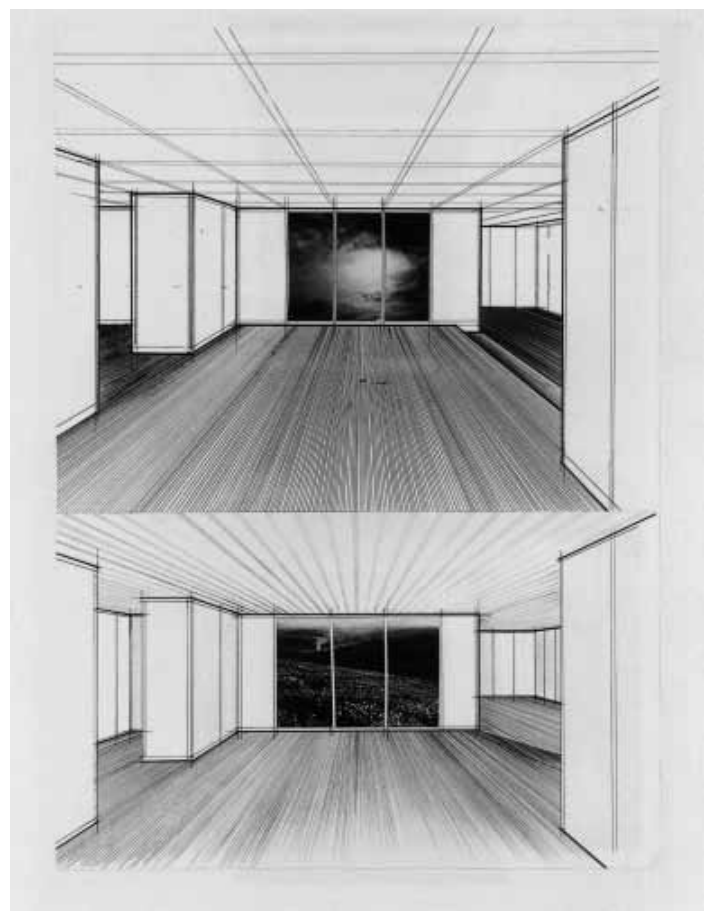

Fig. 2. Habitaciones, 1971, $66.7 \mathrm{~cm}$ x $51.7 \mathrm{~cm}$, Panel de Atlas de Gerhard Richter, $\mathrm{n}^{\circ} 236$. pegada en paneles, una tras otra y ahí surgen relaciones, destellos fugaces que evidencian sus propiedades ocultas. En el momento en que cambian de sitio, el artista reconfigura el orden de las cosas. Esto confiere otra legibilidad ${ }^{16}$ a la imagen singular y al conjunto que vive de los nexos entre los elementos y deja paso a la dimensión imaginativa, aquella que Baudelaire magníficamente definía, en su ensayo sobre Poe, como: "una facultad casi divina que percibe ante todo, desde fuera de los métodos filosóficos, las relaciones íntimas y secretas de las cosas, de las correspondencias y las analogías" ${ }^{17}$.

Un atlas proporciona un campo donde ejercitarse, testar repeticiones y diferencias, experimentar disponiendo imágenes en el espacio e investigando la naturaleza de la percepción. La función didáctica no está del todo ausente del Atlas, sin embargo, por su azarosa heterogeneidad, es más oportuno hablar de un uso de ésta

15 ELGER, Dietmar y OBRIST, Hans Ulrich (eds.), Gerhard Richter: Text, Writings, Interviews and Letters 1961-2007, Thames and Hudson, Londres, 2009, p. 350.

16 Nos recuerda Didi-Huberman que tenemos la posibilidad de leer de dos maneras: "un sentido denotativo en busca de mensaje, un sentido connotativo en busca de montaje", DIDI - HUBERMAN, Georges (2010), op. cit., p. 16.

17 BAUDELAIRE, Charles, Edgar Allan Poe, Madrid, Visor, 1988, p. 98. 
sólo por parte del autor, mientras el espectador queda excluido. Estamos lejos de los atlas de imágenes de finales de los años veinte, eminentemente didácticos y epistemológicos como los de Aby Warburg o de Agust Sander ${ }^{18}$. En el Antlitz der Zeit de 1929, el fotógrafo quiere catalogar de manera científica enteras generaciones y clases sociales de alemanes, como típicos de un pueblo. Esta obra de carácter monumental, como también el Mnemosyne, por su carácter irónico y directo, encuentra el veto de la censura nazi. Walter Benjamin se dio cuenta del valor del proyecto: "la obra de Sander es algo más que una colección de fotografías: es un atlas sobre el que ejercitarse" ${ }^{19}$. Este comentario de Benjamin indica el reconocimiento de la voluntad de Sander por abarcar no solamente la totalidad de las tipologías de la sociedad alemana, sino también la finalidad didáctica de su obra. Los atlas sirven para aprender; los de geografía, por ejemplo, para conocer las coordinadas de mares, montañas, lagos, etc. y reconocer en un mapa las posiciones de los continentes, estados, regiones, ciudades, etc. El de Richter no llega a tener una funcionalidad didáctica para el espectador, para el artista quizá sí, porque va añadiendo regiones conocidas a su geografía visual; como en aquellos mapas en blanco, donde el alumno tenía que escribir el nombre de ríos, provincias, ciudades, estados, etc. De esta forma el artista coloca imágenes y crea regiones, áreas semántico-formales que va construyendo poco a poco.

\section{Contexto}

Richter se formó culturalmente y artísticamente en la República Democrática Alemana. Bajo el control del régimen soviético no había medios de comunicación masivos repletos de imágenes fotográficas y publicitarias. Al huir de su país y llegar a la parte occidental de Alemania, el artista vive un cambio cultural que afecta a su percepción de las imágenes y del mundo. Acercarse a la realidad a través del medio fotográfico implica un distanciamiento por su parte. La realidad mediática alcanza un nivel de proliferación tal, que no solamente es una parte de la vida cotidiana, sino que es la vida cotidiana. Esta sustitución había sido individuada por Kracauer décadas antes: "el torrente de fotos arrasa sus diques. El aluvión de las colecciones de imágenes es tan poderoso que amenaza con destruir la conciencia, quizá existente, de rasgos decisivos. Las obras de arte padecen el mismo destino por su reproducción. [...] Hasta ahora nunca una época supo tan poco sobre sí misma. La elaboración de las revistas está en manos de la sociedad dominante de uno de los medios polémicos más poderosos surgido contra el conocimiento. [...] La "idea de imagen" expulsa a la idea inicial; el torbellino de nieve de las fotogra-

18 A los que cabe añadir los de Kart Blossfeld (Unformen der Kunst, 1928) y de Hannah Höch (Media Scrap Book, 1933).

19 BENJAMIN, Walter, "Piccola storia della fotografía", en L'opera d'arte nell'epoca della reproducibilitá tecnica, Torino, Einaudi, 2000, p. 73. 

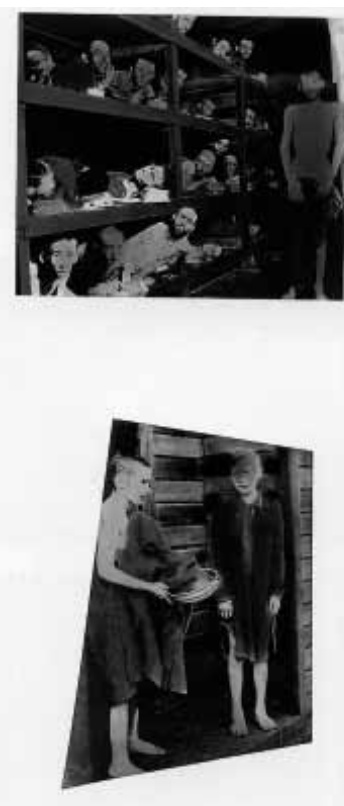

Fig. 3. Fotografías de libros, 1967, $66.7 \mathrm{~cm} \times 51.7 \mathrm{~cm}$, Panel de Atlas de Gerhard Richter, $\mathrm{n}^{\circ} 20$.

fías revela la indiferencia frente a lo que a las cosas se refiere. No debería ser así; sin embargo, las revistas norteamericanas, a las que, las de otros países emulan frecuentemente, sin duda equiparan el mundo con la esencia de las fotografías" ${ }^{20}$.

Durante un año y medio, recién llegado al Oeste, trabaja en una tienda de fotografía, donde recuerda que: "los montones de fotografías que pasaban por el baño revelador día tras día tal vez me produjeron un trauma permanente" 21 . Este trauma, provocado por aquella multitud de imágenes que aparecían poco a poco bajo la superficie del líquido revelador en un cuarto oscuro, se manifiesta ahora como repetición del gesto de acumulación de imágenes. La destrucción de la conciencia de "rasgos decisivos" que evidenciaba Kracauer apunta justamente a la dificultad de diferenciar y orientarse en la iconosfera. Los detalles decisivos son los que identifican una imagen, agarrarlos implica su comprensión. Quizá este caos insoportable de imágenes indiferenciadas haya empujado al artista hacia la necesidad de construir un cosmos idiosincrásico, pero ordenado. Reutilizar los fragmentos para estructurar su propio imaginario visual, a través de un grado de conciencia mayor. Podríamos avanzar la hipótesis que el Atlas constituya un cotidiano ordenamiento de la mesa de trabajo de Richter, un intento de reconstruir un mundo dividido en pequeños fragmentos, movidos a paneles que los acogen y permiten su análisis, como si de una mesa de disección se tratara.

Hans - Peter Feldmann, que vive y trabaja en la misma situación histórico-cultural, es otro testigo de la invasión de las imágenes mediáticas que también entran a formar parte de su trabajo, "su labor consiste en contraponer al caos del mundo una construcción artística, y al mismo tiempo hacer florecer el cosmos de nuestra imaginación" 22 . Consideración que puede aplicarse también al caso de Richter. Las primeras imágenes del Atlas parecen cargadas de cierta nostalgia, de una carga

\footnotetext{
20 KRACAUER, Siegfried, La fotografía y otros ensayos, Gedisa, Barcelona, 2008, pp. 32-33.

21 RICHTER, Gerhard (2003), op. cit., p. 18.

22 WESKI, Thomas, en TATAY, Helena (dir.), Hans-Peter Feldmann, 272 pages, Fundació Antoni Tàpies, Barcelona, 2001, p. 319.
} 
emocional relativa a un entorno íntimo que el artista tuvo que dejar atrás. Parecen haber sido arrancadas del álbum familiar. El cambio radical de contexto tanto geopolítico como personal, lleva consigo, ya a partir del quinto panel, el encuentro impactante con los géneros culturales de masas de Occidente. Por primera vez, Richter puede examinar abundantemente las categorías iconográficas de la sociedad de consumo: moda, viajes, pornografía y publicidad, entre otras ${ }^{23}$. Una heterogeneidad y una abundancia tales que imponen al artista que trate de poner orden. Actitud que comparte con otros artistas de la época, como el mismo Feldmann, los Becher, Ruscha, Saura ${ }^{24}$, Boltanski, Rabascall, LeWitt, Brecht, etc.

"El Atlas de Gerhard Richter es uno entre distintos proyectos estructuralmente similares, creados por una serie de artistas europeos desde principios a mediados de los sesenta, cuyos procedimientos formales de acumular fotografías - encontradas o producidas deliberadamente en disposiciones reticulares más o menos regulares han continuado planteando un enigma". ${ }^{25}$

El Atlas no propone tipologías o fotomontajes y tampoco llega a tener el rigor propio de un modelo epistémico sino que propone rizomas, multiplicidades y muchas carreteras perdidas. Un enfoque que tiene tanto de incertidumbre ${ }^{26}$ como de dinamismo heurístico. Escriben Deleuze y Guattari, que "no se trata ya exactamente de extraer constantes a partir de variables, sino de poner variables en estado de variación continua" 27 . El término "variables" es útil a la hora de hablar del Atlas, porque si observamos, por ejemplo, los numerosísimos paneles dedicados al paisaje, nos damos cuenta que las diferencias entre las imágenes de un mismo panel son mínimas. Como si pertenecieran al mismo carrete fotográfico. Se trata simplemente de pequeños cambios de encuadre ${ }^{28}$. No hay contraste ni una disposición asociativa entre las imágenes. Quizá cada pieza se corresponde a un acercamiento, un paso más hacia lo que busca Richter. "Veo un número infinito de paisajes, fotografío menos de uno cada 100.000, pinto quizá uno de cada cien paisajes fotografiados, así estoy buscando algo bastante específico; por esto, puedo concluir que sé lo que quiero"29. De todas las imágenes que encuentra, Richter se

23 BUCHLOH, Benjamin H. D. (1999), op. cit., p. 161.

24 Escribe Antonio Saura a propósito de su obra de acumulación: "reflejo de la necesidad de apropiación del cotidiano universo de imágenes y de su transformación bajo conceptos de superposición, acumulación y metamorfosis. Multiplicidades de la imagen subjetiva que provoca una discontinuidad global del resultado." SAURA, Antonio, Antonio Saura. Por sí mismo, Lunwerg, Barcelona, 2009, p. 239.

25 BUCHLOH, Benjamin H.D. (1999), op. cit., pp. 147-148.

26 "Incertidumbre en cuanto a una orientación creíble y plásticamente convincente del arte de nuestra época”. ROCHLITZ, Rainer (1999), op. cit., p. 248.

27 DELEUZE, Gilles y GUATTARI, Felix, en DIDI - HUBERMAN, Georges (2010), op. cit., p. 52.

28 Véanse los paneles 456, 457, 458, 459, 463, 464, 465, 466, 467, entre los muchísimos ejemplos posibles resulta más complicado encontrar paneles cuyas imágenes contrasten por tema y formatos, con la gran excepción de los primeros paneles.

29 "I see countless landscapes, photograph scarcely one in 100 000, painting hardly one in 100 photographed landscapes - I am therefore looking for something quite specific; from this I can conclude that I know what I want" FRIEDEL, Helmut (dir.) (2006), op. cit., pp. 5-6. 
siente atraído especialmente por las más banales, son éstas las que más "desbordan de vida" ${ }^{\prime 0}$ y que más se prestan a ser usadas y transformadas en pinturas.

\section{Atlas}

El Atlas tiene que algo que ver también con la tradición de los Skizzenbuch, cuadernos de bocetos rápidos utilizados por los maestros antiguos para retener las imágenes del mundo, de lo llamativo y su interpretación gráfica. El mundo de Richter es mediatizado, retenido por la cámara, impreso en una revista o en papel sensible. Parecen imágenes mecánicas y objetivas, pero presentan una realidad disfrazada, cortada y deformada, sin embargo, siguiendo la ontología de Roland Barthes, cuando miramos una fotografía no podemos dejar de decir ¡esto ocurrió! ${ }^{31}$. El Atlas es un diario que presenta la personal preocupación del artista por el problema de la representación, que sin tener la coherencia del archivo, presenta una personal arqueología visual. La mayoría de los temas presentes aparecen en series o secuencias ${ }^{32}$, en contadas ocasiones un panel presenta una sola imagen, que alcanza el estatus de icono ${ }^{33}$. Cuando esto ocurre, la fotografía está enmarcada por cinta o completada con líneas y colores. La relación entre las imágenes parece ser el punto fundamental del Atlas, las pequeñas diferencias, aquel detalle que podría marcar la diferencia entre una simple imagen y un emblema. El Atlas se columpia entre un deseo de orden y la completa destrucción de esta promesa. Escribe Georges Didi-Huberman: "Contra toda pureza estética [el atlas] introduce lo múltiple, lo diverso, la hibridez de todo montaje" ${ }^{34}$.

\section{Un antiarchivo ${ }^{35}$ de lo banal}

En su extensa mayoría el Atlas comprende fotografías ${ }^{36}$, materia que sirve a Richter como punto de partida para ulteriores transformaciones. Como en el caso de

30 CHEVRIER, Jean-Francois (1999), op. cit., p. 173.

31 BARTHES, Roland, La camera chiara. Nota sulla fotografia, Einaudi, Torino, 2003, p. 78.

32 En efecto, cada panel del Atlas es una serie, su totalidad es una serie de series. Empezamos mirando una sola imagen, de allí a la siguiente y otra y otra. Un paso después de otro, y así sucesivamente. En este escenario, el trabajo de Richter tendría sentido sólo para él. Evidentemente es una instrumento de aprendizaje, un cuaderno de notas y una colección de pro-memoria y apuntes a lo que, el artista vuelve constantemente.

33 Véanse los paneles: de 138 a 141, de 196 a 198, 616.

34 DIDI - HUBERMAN, Georges (2010), op. cit., p. 15.

35 En una célebre conferencia Derrida dijo que el archivo se forma al archivar. El principio determina el contenido y la forma del archivo. En el caso de Richter el principio no es tan riguroso y la forma de su colección varía tanto que el término "antiarchivo" nos parece correcto, además en parte recoge las indicaciones de Buchloh que habla de "archivo anómico", sin embargo lo despojamos de la evidente paradoja que tal definición implica. Véase DERRIDA, Jacques, Mal de Archivo. Una impresión freudiana, Trotta, Madrid, 1997, pp. 9-10.

36 "La Documenta X expuso ciertamente el Atlas fotográfico de donde Richter extrae sus motivos, a título de obra de arte, pero es dudoso que hay que inscribir a Richter en la historia de la fotografía; en la mayoría de fotos utilizadas por él, lo que importa es el carácter no artístico." ROCHLITZ, Rainer (1999), op. cit., p. 246. 


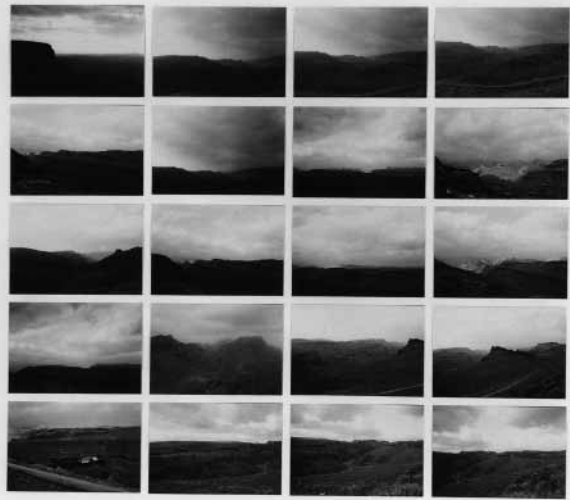

Fig. 4. Paisajes, 1985, $51.7 \mathrm{~cm}$ x $66.7 \mathrm{~cm}$, Panel de Atlas de Gerhard Richter, ${ }^{\circ} 372$.
Andy Warhol, la imagen fotográfica es el gran referente visual contemporáneo, mientras la pintura se relega a un ámbito elitista. La herencia de la pintura está desde su comienzo presente en la historia de la fotografía, y para estos dos artistas "la contingencia indicial de la fotografía se ha convertido en signo pictórico, y al mismo tiempo, de testimonio de la existencia factual que antes era, se ha convertido en signo emblemático"37.

Richter se autodefine pintor de historia y busca la imagen "correcta", apta para pasar del estadio de la contingencia al emblema del momento "en el que nos hallamos"38. Sin embargo, es una tarea titánica, por esto quizá Richter decide emprenderla en nombre de Atlas, condenado a llevar el mundo a cuestas, a sostener con sus hombros todos aquellos fragmentos que se balancean entre lo privado y lo histórico, lo individual y lo universal. De este universo visual, el pintor quiere rescatar aquella imagen justa, tan representativa de su género que es capaz de elevarse al rango de emblemática. La elección del artista de recurrir al Atlas es sintomática de una profunda incertidumbre hacia la tarea de la pintura ${ }^{39}$. Inseguridad que trata de superar procediendo por reiterados asaltos, y con suerte alterna, a toda la esfera de imágenes posibles. Confortado en esta tarea por la jouissance del pintar. El numero de imágenes que lo constituyen es quizá lo que más asombra del Atlas, pero es curiosa también la reiteración del mismo tema a lo largo de todo un panel, grupos de 6, 9, 12 o 16 imágenes; aparentemente, vistas convencionales tomadas por un turista, no muy diestro con la cámara, durante sus vacaciones. Ahora nos preguntamos ¿por qué este tipo de fotografías?

"Richter busca captar un exceso de descripción. Le atraen mucho más las instantáneas "banales" que las fotografías "artísticas, compuestas"; éstas últimas le parecen "imágenes profundamente empobrecidas, con su juego de luz y sombra, sus armonías y efectos compositivos. En cambio, la foto familiar, donde todo el mundo aparece bien plantado en el centro de la imagen, desborda literalmente de vida". ${ }^{40}$ Richter tacha de "foto familiar" a las imágenes banales o antiartísticas,

37 Ibid., p. 244.

38 Ibid., p. 262.

39 "La exploración de un vasto repertorio formal parece ser a la vez un signo de desconcierto ante la función del arte y un signo del gusto por la experimentación.” En ibid., p. 262.

40 CHEVRIER, Jean-Francois (1999), op. cit., p. 173. 


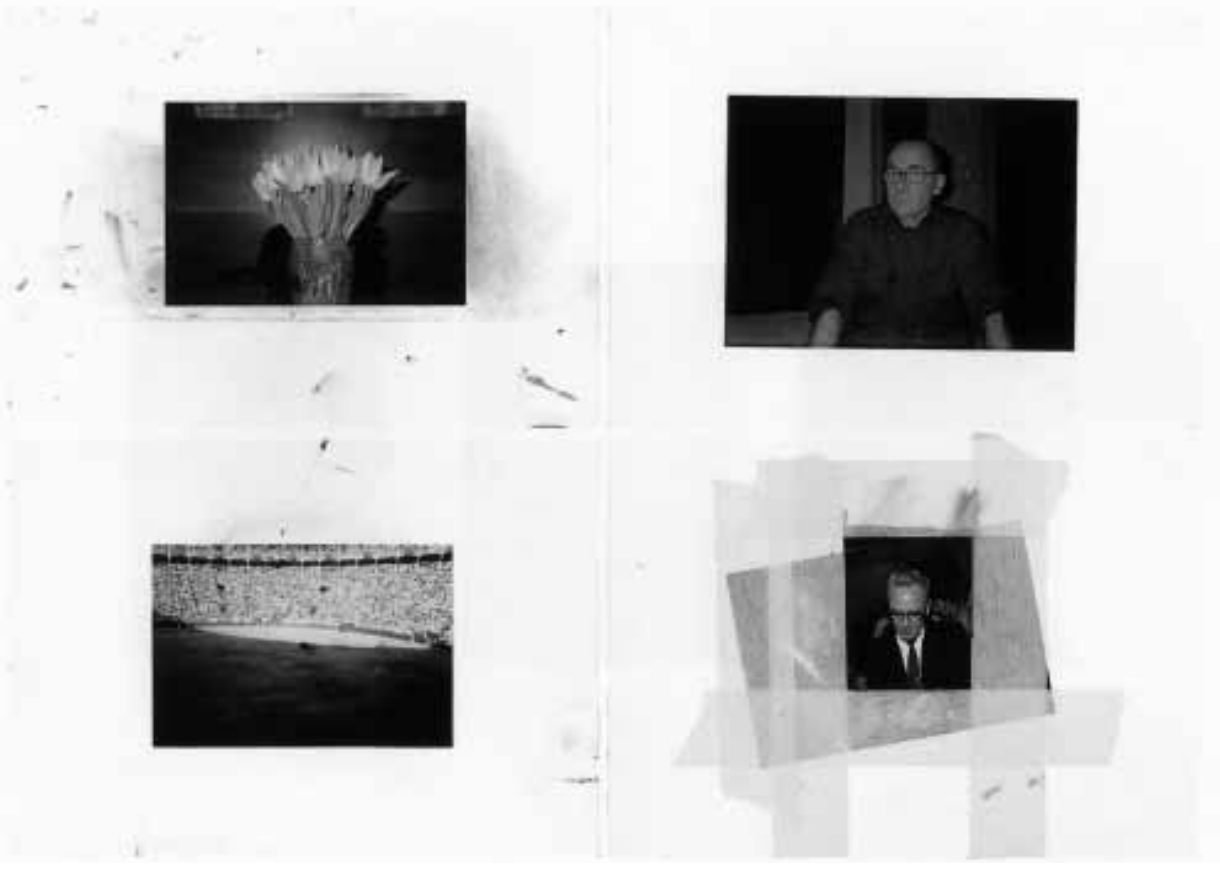

Fig. 5. Motivos varios, $51.7 \mathrm{~cm}$ x $66.7 \mathrm{~cm}$, Panel de Atlas de Gerhard Richter, $\mathrm{n}^{\circ} 618$.

porque estos tipos de fotos normalmente interesan a los familiares que las protagonizan, por motivos personales, ligados al recuerdo de una persona querida o a la circunstancia en que se tomó. ¿En qué consiste este "desbordamiento de vida" al que alude el artista? Roland Barthes en La chambre claire, habla de esta esfera emotiva, de un recuerdo involuntario que deja al margen todo problema estético, histórico y sociológico de este arte: "la foto me emociona si la retiro de su cháchara ordinaria: técnica, realidad, reportaje, arte, etc.: no decir nada, cerrar los ojos, dejar que el detalle aflore a conciencia afectiva" ${ }^{41}$ Testigo mudo de emociones personales, pero quizá en esta dirección se dirige lo que el artista se propone: extraer lo general de lo particular, convertir en emblema una contingencia. Entonces, nos damos cuenta, que su interés avanza en otras direcciones respecto a la propuesta por Barthes y se acerca más bien a las "pinturas de imágenes comunes", las que Ivan Karp encontraba en el por art americano de Warhol y Lichtenstein. El impacto emocional de las fotografías de aficionados es quizá mayor que él de las fotografías artísticas, porqué esta falta de un calculado formalismo abre, por empatía, al contenido existencial. Éste, sin ser mediatizado por el dominio de la técnica, se presenta directo y

${ }^{41}$ KRAUSS, Rosalind E., Lo fotográfico: por una teoría de los desplazamientos, Gustavo Gili, Barcelona, 2002, p. 14. 
"común" "42. En esta inmediatez no programada Richter halla aquel desbordamiento que le interesa. Escribe el artista: "la fotografía te impide estilizar, ver "mal", dar una interpretación demasiado personal del tema. [...] Una foto ya es un pequeño cuadro, aunque todavía no lo es del todo. Ese carácter es irritante y te impulsa a desear transformarla definitivamente en un cuadro". ${ }^{43}$

El artista identifica el "ver mal" con un estilo idiosincrásico, y se nota la voluntad de alejarse tanto del arte informal como del expresionismo abstracto. Richter aboga por representaciones, donde el "yo" se difumina hasta desaparecer; oculto en múltiples directrices, como en el Altas. "Me gustan las cosas sin estilo: los diccionarios, las fotografías, la naturaleza, yo mismo y mis cuadros. (Porque estilo equivale a violencia y yo no soy violento). ${ }^{44}$

En esta dirección se puede hablar también de ready-made o quizá más propiamente de objet trouvé, hablando del material que se colecciona en el Atlas ${ }^{45}$. Puntos de partida que permiten al artista prescindir, lo más posible, de la tradición pictórica y de sus legados tanto temáticos como formales.

\section{Retícula}

"Quiero dejarlo todo tal y como es. Por eso no planifico, invento, ni quito nada, sabiendo al mismo tiempo que de hecho, no puedo evitar planificar, inventar, modificar, hacer y manipular [...] Quiero tener las cosas claras, sencillas y sin condiciones, y preferiría no crear nada antes que hacer cualquier pintura indefinida"46. Este afán de claridad se manifiesta también en la organización reticular del Atlas. Sin embargo, la disposición reticular, aparentemente neutral, implica, por lo contrario, que: "los objetos van quedando rebasados gradualmente por la matriz que los mantiene en su sitio, la cuadrícula que los sitúa y los aplana, el método que los ensarta como ejemplares en otros tantos espacios categóricos; una vida se transforma así en un sistema taxonómico" ${ }^{47}$. Krauss se refiere a Autobiography, un libro fotográfico de Sol LeWitt de 1980, donde más de mil instantáneas del estudio del artista estaban dispuestas en retículas que contenían 9 fotografías por cada página. La retícula es también el método de organización del material del Atlas. Ésta implica una falta de jerarquía a la vez que lleva a una lectura "diagramática" que permite una serie de asociaciones y relaciones vinculadas con la imaginación del espectador. Se trata de

42 CHEVRIER, Jean-Francois (1999), op. cit., p. 171.

43 Ibid., p. 173.

44 RICHTER, Gerhard (2003), op. cit., p. 21.

45 "La fotografía es la imagen más perfecta: no cambia, es absoluta y por tanto autónoma, incondicional y carente de estilo. En la manera en que habla y en lo que dice, la tomo como modelo" Ibid., p.18.

46 Ibid., p. 20.

47 KRAUSS, Rosalind, en GUASCH, Anna Maria, Autobiografias visuales. Del archivo al índice, Siruela, Madrid, 2009, p. 68. 
un sistema de organización de imágenes en un espacio. Un sistema que podemos relacionar no solamente con aquella pérdida del aura que nos impide contemplar detenidamente una sola imagen, y que, viceversa, nos empuja a pasar a otra y luego a otra más, sino que además se vincula con la concepción, también benjaminiana, de la "imagen dialéctica" y por ende del método de conocimiento histórico basado en el montaje.

\section{Montaje}

Los "trascendentales" del montaje, entendidos kantianamente como las condiciones de posibilidad, son, según Agamben, la repetición y la interrupción ${ }^{48}$. En el Atlas las repeticiones se encuentran en aquellos pequeños matices entre las imágenes que constituyen los paneles, enfati-
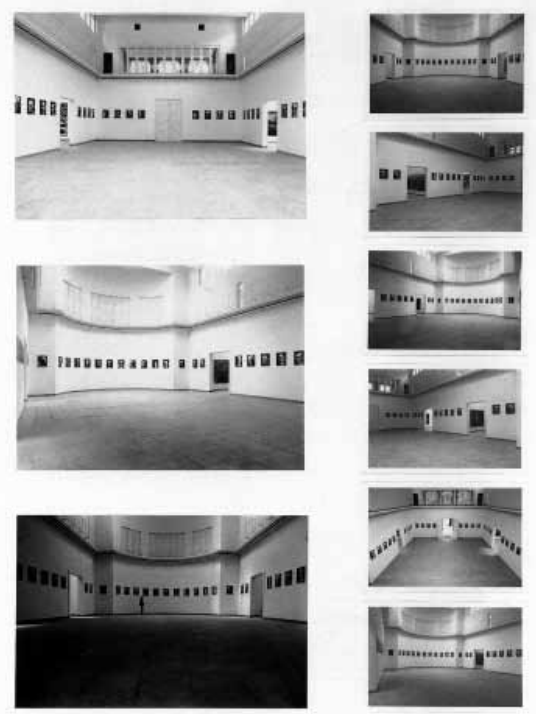

Fig. 6. Para una instalación " 48 Retratos" (Bienal de Venecia 1972), 1972, $66.7 \mathrm{~cm}$ x $51.7 \mathrm{~cm}$, Panel de Atlas de Gerhard Richter, ${ }^{\circ} 41$. zados por su unidad semántica y formal.

En cambio, las interrupciones son aquellos espacios blancos entre las imágenes, que la disposición reticular crea. Intersticios donde Richter, ocasionalmente, interviene con colores, lápices o cinta aislante, o bien ampliando sus dimensiones ${ }^{49}$.

Agamben define la repetición, refiriéndose a un amplia tradición filosófica que incluye Kierkegaard, Nietzsche, Heidegger y Deleuze, como "la restitución de la posibilidad de lo que ha sido, lo que lo hace posible de nuevo". Característica que conecta la repetición con la memoria que, siempre según el filósofo, "restituye al pasado su posibilidad" 50 . Trabajar con las imágenes tiene una importancia fundamental, porque permite "proyectar la potencia y la posibilidad hacia lo que por definición es imposible, hacia el pasado" 51 . En sentido radicalmente opuesto a los medios masivos que restituyen solo hechos (o presuntos tales), despojados de sus posibilidades. En su concepción del término interrupción, Agamben se refiere tanto a la "interrupción revolucionaria" de Benjamin, como al corte, es decir, la

48 AGAMBEN, Giorgio, "Il cinema di Guy Debord”, en GHEZZI, Enrico y TUGLIATTO, Roberto, Guy Debord (contro) il cinema, Il Castoro, Milano, 2001, pp. 103-107. 746.

49 Véanse los paneles 57, 91, 95, 96,127,128, de 445 a 451, de 526 a 529, 575, de 656 a 666, de 737 a

50 AGAMBEN, Giorgio (2001), op. cit., p.105.

51 Ibid., p. 106. 
respiración de la poesía según Hölderlin. La interrupción, "no es simplemente una pausa", sino una no coincidencia, una encrucijada entre el sonido y el sentido. Un intersticio fecundo que substrae la imagen de su contexto narrativo y la presenta en cuanto imagen, con sus "rasgos decisivos" y sus posibilidades. Agamben, que retoma un principio teórico de la Société du spectacle, define la imagen como una "zona de indecisibilidad entre lo verdadero y lo falso" 52 , si ésta se produce a través de la repetición y de la interrupción, no resuelve esta contradicción, sino que se muestra en toda su dialéctica no resuelta, como "una bola de fuego que atraviesa todo el horizonte del pasado" 53 . El montaje supone el desmontaje, Richter procede en este sentido cuando coleccionas los trozos de lo real que encuentra en fotografías, recortes o en sus esbozos. Sin embargo, es preciso diferenciar entre una metodología rigurosa y epistemológica (Warburg, Benjamin) y la del artista, estética e idiosincrásica. Al margen de esto, en el Atlas es donde se hace más evidente la voluntad de Richter de poner a prueba su visión del mundo y las posibilidades del arte en un continuo juego metonímico.

"Benjamin afirma que la imagen dialéctica no es "algo que se desarrolle, sino una imagen entrecortada". [...] el montaje como procedimiento supone en efecto el desmontaje, la disolución previa de lo que construye, de lo que en suma no hace más que remontar, en el doble sentido de la anamnesis y de la recomposición estructural" ${ }^{\prime 5}$

\section{Conclusiones}

El Atlas es un trabajo de cada día. Richter mira, elige, corta y pega. Organiza y ordena su cosmos artístico. En el Atlas cada espectador crea su propio relato, vista la total ausencia de directrices, nombres e indicaciones. Esto no implica solamente una contemplación activa, sino que además, propone una heurística, el arte y la ciencia del descubrimiento, de la invención o del resolver problemas mediante la creatividad y el pensamiento lateral.

Probablemente, considerar el mundo sumergido de simulacros, donde la única realidad a la que tenemos acceso es mediatizada y mistificada como indica Baudrillard, es ir demasiado lejos. Para el filósofo francés, toda imagen es falsa. Sin embargo, este riesgo existe. Por esta razón, aislar los fragmentos, desplazarlos en otro contexto, activa y proporciona una nueva visión, más consciente del medio al que nos enfrentamos e incluso desafiante. Resistir consiste en "tener la fuerza de de-crear lo que existe, de-construir lo real" 55 ; y escribe Benjamin: "el placer que

\footnotetext{
Ibid., p. 106.

DIDI -HUBERMAN, Georges, Ante el tiempo, Adriana Hidalgo, Buenos Aires, 2005, p. 150.

Ibid., p. 156.

5 AGAMBEN, Giorgio (2001), op. cit., p. 107.
} 
brinda el mundo de las imágenes [...] se nutre de un sombrío desafío lanzado al saber" ${ }^{\prime 56}$. El conocimiento, que aquel titán está condenado a llevar a cuesta, es el lo que Richter trata de alcanzar. Pretende discernir aquellas (pocas) imágenes emblemáticas, verdaderas herramientas de pensamiento, que pueden "despertar" la memoria que restituye las posibilidades al pasado.

Finalmente, el Atlas puede representar un distanciamiento necesario. La toma de conciencia de una separación irremediable entre el "yo" y el mundo, que se coloca entre los dos focos de un elipse cuya área contiene todas las imágenes, reales y posibles.

"El acto de interponer una distancia entre uno mismo y el mundo exterior puede calificarse de acto fundacional de la civilización humana; cuando este espacio interpuesto se convierte en sustrato de la creación artística, se cumplen las condiciones necesarias para que la conciencia de la distancia pueda devenir una función social duradera, [...] la suficiencia o el fracaso de la cual, como instrumento espiritual orientador, determina el destino de la cultura humana" 57 .

56 DIDI -HUBERMAN, Georges (2005), op. cit., pp. 195-196.

57 WARBURG, Aby, Atlas Mnemosyne, Akal, Madrid, 2010, p. 3. 